\title{
Lobe of Origin and Histologic Type of Lung Cancer Associated With Asbestos Exposure in the Carotene and Retinol Efficacy Trial (CARET)
}

\author{
C. Andrew Brodkin, MD, MPH, ${ }^{1,2 *}$ J oel McCullough, MD, MPH, ${ }^{1}$ Bert Stover, BA $^{1}$ \\ John Balmes, MD ${ }^{3}$ Samuel Hammar, MD, ${ }^{1}$ Gilbert S. Omenn, MD, PhD, ${ }^{1,2}$ \\ Harvey Checkoway, $\mathrm{PhD}^{1}$ and Scott Barnhart, MD, $\mathrm{MPH}^{1}$
}

\begin{abstract}
Lower lobe origin and histologic diagnosis of adenocarcinoma have been described as useful parameters for attributing lung cancer to prior asbestos exposure. To assess whether these characteristics differed between asbestos-exposed individuals and smokers, we evaluated lobe of origin and histologic type of tumors in 78 asbestos-exposed and 214 nonexposed heavy smokers developing lung cancer during the Carotene and Retinol Efficacy Trial (CARET), a prospective cancer chemoprevention trial. Most tumors in both cohorts, regardless of radiographic fibrosis at baseline, originated in upper lobes, representing 67\% in asbestosexposed and $80 \%$ in smokers, respectively (adjusted OR for lower lobe $=1.41 ; 95 \% \mathrm{CI}=$ 0.69-2.91). Adenocarcinoma represented 32\% of lung tumors in the asbestos cohort, and $30 \%$ in the smoking cohort (adjusted $\mathrm{OR}=0.78 ; 95 \% \mathrm{CI}=0.40-1.55$ ), and was inversely associated with radiographic fibrosis (adjusted OR $=0.19 ; 95 \% C I=0.06-0.62$ ). We conclude that neither anatomic site nor histologic cell type of tumors distinguishes effectively between smoking and asbestos as causal factors in development of lung cancer. Am. J. Ind. Med. 32:582-591, 1997. @ 1997 Wiley-Liss, Inc.
\end{abstract}

KEY WORDS: lung neoplasms; asbestos; asbestosis; histology; pneumoconiosis; pulmonary fibrosis; retinoids; anatomy, regional; lung diseases, interstitial; smoking

\section{INTRODUCTION}

The synergy between cigarette smoking and asbestos exposure poses a clinical challenge in determining causation of lung cancer in individuals exposed to both agents. Lung cancer in the general population, chiefly related to smoking,

\footnotetext{
IUniversity of Washington, Department of Environmental Health, Seattle, Washington

${ }^{2}$ Fred Hutchinson Cancer Research Center, Seattle, Washington

3 University of California, San Francisco, California

Contract grant sponsor: National Cancer Institute; Contract grant number: U01 CA63673; Contract grant number: U01 CA63674; Contract grant number: U01 CA47989; Contract grant number: U01 CA48200; Contract grant number: U01 CA48203; Contract grant number: U01 CA48196; Contract grant number: U01 CA52596.

*Correspondence to: C. Andrew Brodkin, Occupational and Environmental Medicine Program, Harborview Medical Center, Box \# 359739, 325 9th Avenue, Seattle, WA 98104; E-mail: werd@u.washington.edu
}

originates primarily in the upper lobe, with an incidence of 25.5 cases $/ 10^{5}$ compared to only 10.5 cases $/ 10^{5}$ for lower lobe tumors, and a predominance of squamous cell carcinomas [Travis et al., 1994]. It has been suggested that asbestos-related pulmonary fibrosis, which involves primarily the lower lobes [Soutar et al., 1974], affects both lobe of origin [Craighead and Mossman, 1982; Talcott, 1988] and histologic cell type [Kannerstein et al., 1972; Whitwell et al., 1974; Craighead and Mossman, 1982] of tumors in exposed individuals, with a propensity for lower lobe anatomic site and "scar-related" adenocarcinomas [Auerbach et al, 1979; 1984; Browne, 1986; Talcott et al., 1988]. A number of studies have described lower lobe of origin, histologic diagnosis of adenocarcinoma, and concomitant radiographic pulmonary fibrosis [Hughes and Weill, 1991] as useful parameters in attributing lung cancer to prior asbestos exposure in clinical and medicolegal settings [Weiss, 1988]. An association between these factors and lung cancer in the setting of asbestos exposure would also have implications 
regarding the pathogenesis of asbestos-related tumors, suggesting that the fibrogenic effect of asbestos plays an essential role in carcinogenesis.

Although the association between asbestos exposure and development of lower lobe tumors, adenocarcinomas, and concomitant findings of radiographic fibrosis has been demonstrated in some studies, others have failed to demonstrate these characteristics [Hillerdal et al., 1984; Auerbach et al., 1984; Kipen et al., 1987; Vainio and Boffetta, 1994; de Klerk et al., 1996]. Despite important public health and medico-legal implications, most studies to date have been limited by small sample size and retrospective study designs, such as surgical and autopsy series, with a strong potential for selection and recall bias.

To address these limitations, we prospectively assessed lobe of origin, histologic type, and presence of concomitant radiographic pulmonary fibrosis in all asbestos-exposed participants in the Carotene and Retinol Efficacy Trial (CARET) who developed lung cancer over a follow-up period of up to 10 years, comparing them to trial participants with a history of heavy smoking but no occupationallyrelated exposure to asbestos.

\section{METHODS}

\section{Case Selection}

This analysis included participants developing lung cancer among the 4,060 asbestos-exposed workers and 14,254 smokers enrolled in CARET. CARET was a National Cancer Institute (NCI)-funded multicenter randomized prospective chemoprevention trial of the safety and effectiveness of 25,000 IU/day retinyl palmitate and $30 \mathrm{mg} /$ day $\beta$-carotene in preventing lung cancer [Omenn et al., 1993, 1994]. Accrual for the pilot phase of the study began in 1985 which was expanded into a full-scale "Efficacy" trial in 1989; 18,314 participants had been randomized by 1994, with a mean follow-up period of 4.0 years when active intervention was halted in January, 1996 [Omenn et al., 1996]. Written informed consent was obtained from all participants, and CARET activities were reviewed and approved annually by institutional review boards at the six CARET study centers. Study subjects for this investigation included 304 participants developing lung cancer, for whom complete clinical and histologic review had been completed at the time study vitamin intervention was terminated.

Eligibility criteria have been described previously for the asbestos-exposed worker cohort [Brodkin et al., 1993; Omenn et al., 1993; Barnhart et al., 1997]. Briefly, the criteria included: age between 45 and 69 years at enrollment; male gender; extensive occupational exposure to asbestos, defined as greater than 5 years of employment in a high-risk trade, or chest radiograph with evidence of asbestos-related effects. Eligibility criteria for the heavy smoking cohort included: age between 50 and 69 years; male or female gender; history of $\geq 20$ pack years of smoking; and current or former smokers quitting within 5 years. Exclusions for both smokers and asbestos-exposed workers included individuals with history of cancer (other than nonmelanotic skin cancer) within 5 years prior to randomization.

\section{Follow-up and Identification of Endpoints}

Health assessments for all participants were conducted three times per year, with an annual site visit to one of six Study Centers, and two phone calls to participants at four month intervals. All lung cancer endpoints were identified through one of the following mechanisms: notification by the participant, next of kin, or treating physicians; cancer registries, death certificates, or state boards of health.

All reports of incident cancers were reviewed by the CARET Endpoints Committee. After obtaining pertinent medical records, the committee confirmed the accuracy and dates of lung cancer diagnoses, as well as the anatomic location of tumors. Clinical and histologic review was completed for 304 participants at the time study intervention was terminated. Twelve participants with multiple cancer sites were excluded, yielding 292 cases, including 78 asbestos-exposed workers and 214 heavy smokers. A specific lobe of origin could not be determined from clinical data in 52 (18\%) participants with extralobar tumors, leaving a total of 240 (82\%) cases, with 73 asbestos-exposed cases and 167 heavy smoking cases, respectively, available for lobe of origin analyses. A histologic determination of single cell type was not possible in $8(3 \%)$ participants with mixed adeno/squamous tumors, nor in $6(2 \%)$ participants with clinically diagnosed tumors, leaving a total of 278 (95\%) cases, with 74 asbestos-exposed cases and 204 heavy smokers, respectively, available for histologic analyses.

\section{Measurements and Observations}

Chest radiographs, obtained for all asbestos-exposed participants at randomization, were scored for pilot participants $(n=816)$ by consensus of two readers and for Efficacy participants $(n=3,244)$ by one reader at each study center trained in the International Labour Office system [ILO, 1980].

Lobe of origin was determined by review of medical records, including chest radiograph, chest $\mathrm{CT}$, and bronchoscopy reports. Upper lobe tumors were identified in 163 (56\%), middle lobe tumors (right) in 19 (7\%), and lower lobe tumors in 58 (20\%) participants. Tumors were identified in prelobar bronchi in $18(6 \%)$, of which $17(94 \%)$ occurred among the heavy smoking cohort and $1(6 \%)$ 
among the asbestos-exposed cohort; no tracheal tumors were observed. The remaining 34 (12\%) participants had tumors located in the mediastinum, hila, interlobar fissures, or extrapulmonary locations. These 52 participants with extralobar tumor sites were excluded from lobe of origin analyses.

Histologic slides and specimens from all incident lung tumors were reviewed by the Coordinating Center pathologist ( $\mathrm{SH}$ ), a specialist in histologic determination of pulmonary neoplasms and mesotheliomas [Dail and Hammar, 1988; Omenn et al., 1996]. There were 264 (93\%) cases classified as one of four major histologic types: adenocarcinoma, squamous cell carcinoma, small cell, or large cell undifferentiated carcinoma. Fourteen (5\%) cases, including sarcomas $(n=2)$, one neuroendocrine tumor, one lymphoma, one basaloid tumor, and other tumors not amenable to classification $(n=9)$ were included in a general category of nonspecified tumors.

\section{Analysis}

Statistical analyses were performed using SPSS for Windows, Version 6.1 software [SPSS Inc., 1995]. Tumors originating in the right middle lobe, which occurred in only 7 asbestos-exposed and 12 nonexposed participants, were combined with right upper lobe tumors and analyzed as non-lower lobe tumors for all analyses. Unadjusted odds ratios (OR) with $95 \%$ confidence intervals (CI) for developing lower lobe tumors were calculated.

To assess the independent effects of study vitamin intervention, demographic criteria, and cumulative and current smoking consumption on the relation between asbestos exposure and tumor lobe of origin and histologic cell type, respectively, logistic regression analyses controlling for these factors were performed. All smoking analyses were performed with both dichotomous assessment of current vs. former smoking, as well as an assessment of pack-years. Adjusted odds ratios with 95\% CI for developing lower lobe lung tumors and adenocarcinoma, respectively, were calculated, with control for age, gender, smoking status, pack-years, and intervention arm (study vitamins vs. placebo). These multivariate analyses were also performed excluding female cancer cases, to eliminate possible confounding due to gender of any association between asbestos exposure and tumor lobe origin or histologic type. Within the asbestos-exposed group, logistic regression analyses were performed to assess the effect of radiographic parenchymal changes and pleural thickening on tumor lobe of origin and histologic cell type, while controlling for the aforementioned potential confounders.

\section{RESULTS}

Seventy-eight asbestos-exposed participants and 214 nonexposed heavy smokers developed solitary lung
TABLE I. Demographic, Smoking, and Vitamin Intervention Status at Randomization for CARET Participants Developing Lung Cancer

\begin{tabular}{lcc} 
& $\begin{array}{c}\text { Asbestos-exposed } \\
\text { cohort } \\
\text { ( } \mathbf{n}=\mathbf{7 8})\end{array}$ & $\begin{array}{c}\text { Heavy smoking } \\
\text { cohort } \\
\text { ( } \mathbf{n}=\mathbf{2 1 4})\end{array}$ \\
\hline $\begin{array}{l}\text { Demographic criteria } \\
\text { Age, mean (SD) }\end{array}$ & \\
Gender (\%) & $63(6)$ & $61(5)$ \\
$\quad$ Male & & \\
$\quad$ Female & $78(100)$ & $121(57)$ \\
Race (\%) & $a$ & $93(43)$ \\
$\quad$ White & & \\
$\quad$ Black & $67(86)$ & $203(95)$ \\
$\quad$ Native American & $10(13)$ & $3(1)$ \\
$\quad$ Other & 0 & $4(2)$ \\
Smoking status (\%) & $1(1)$ & $4(2)$ \\
Current & & $163(76)$ \\
Former & $38(49)$ & $51(24)$ \\
Never & $40(51)$ & a \\
Pack-years, mean (SD) & 0 & $57(22)$ \\
Vitamin intervention armb $\left.{ }^{b} \%\right)$ & $51(23)$ & $126(59)$ \\
Active & & $88(41)$ \\
Placebo & $44(56)$ & \\
\hline
\end{tabular}

aNo participants available.

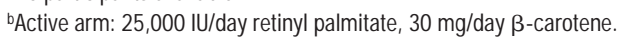

tumors during the CARET intervention period. Demographic, smoking, and vitamin intervention data at enrollment are presented in Table I. Mean age for the asbestos-exposed and smoking groups (63 and 61 year, respectively), racial distribution ( $86 \%$ and $95 \%$ white, respectively), mean pack-years of smoking (51 and 57 pack-years, respectively), and percentage randomized to active vitamin intervention (56\% and $59 \%$ active intervention arm, respectively) were similar for the asbestos-exposed and heavy smoking groups. Differences in current smoking (49\% and $76 \%$, respectively) and gender distribution resulted from the recruitment of active smokers and women in the latter group. No lung cancers were observed among the 132 asbestos-exposed pilot participants who never smoked.

Study eligibility criteria, exposure characteristics, and baseline radiographic changes for the 78 asbestos-exposed participants developing lung cancer are presented in Table II. Participants in this group had a mean cumulative exposure to asbestos of 30 years, with 22 years of exposure in a high-risk trade. Mean latency, defined as the period between first asbestos exposure and enrollment into the CARET study, was 40 years. Only 10 (13\%) asbestosexposed participants who developed lung cancer had normal baseline chest radiographs at randomization; 19 (24\%) had 
TABLE II. Characteristics of Asbestos-Exposed Workers Developing Lung Cancer $(n=78)$ : CARET Study

\begin{tabular}{|c|c|}
\hline Eligibility criteriaa & $\mathrm{n}(\%)$ \\
\hline High-risk trade & $10(13)$ \\
\hline Radiographic changes ${ }^{b}$ & $18(23)$ \\
\hline High-risk trade and radiographic changes & $50(64)$ \\
\hline Asbestos exposure history & yr (SD) \\
\hline Total years exposure & $30(10)$ \\
\hline Years in high-risk trade & $22(15)$ \\
\hline Latency & $40(8)$ \\
\hline Radiographic changes $(\%)$ & $n(\%)$ \\
\hline Normal & $10(13)$ \\
\hline Pleural thickening only & $19(24)$ \\
\hline Parenchymal changes ${ }^{c}$ only & $15(19)$ \\
\hline Pleural and parenchymal changes & $34(44)$ \\
\hline
\end{tabular}

aDescribed in Methods section.

bBased on chest radiograph at enrollment.

clLO profusion $\geq 1 / 0$.

pleural changes only, and 49 (63\%) had radiographic profusion of small opacities ( $\geq$ ILO 1/0).

The lobar distribution of lung cancers developing in the asbestos-exposed and heavy smoking cohorts is presented in Table III. Although there was a significant tendency for development of lower lobe tumors in the asbestos-exposed group (OR for lower lobe $=1.92 ; 95 \% \mathrm{CI}=1.03-3.55)$, the majority of lung cancers in both cohorts originated in upper lobes, with $67 \%$ upper lobe tumors in the asbestos-exposed group and $80 \%$ upper lobe tumors in the heavy smoking group, respectively. Lobar distribution of tumors was similar when stratified by current and former smoking status (Table III); most tumors developed in the upper lobe in both asbestos-exposed workers and heavy smokers across all smoking strata. No subjects were available in the never smoking stratum, because of selection criteria in the smoking group and the absence of incident cases among the small number $(\mathrm{n}=132)$ of never smokers in the asbestos-exposed group. No association between vitamin intervention arm and lobe of origin was observed, with $87(76 \%)$ upper lobe tumors occurring in participants taking study vitamins compared to 74 (74\%) upper lobe tumors in those taking placebo.

The lobar distribution of lung tumors in asbestosexposed participants with and without baseline radiographic evidence of parenchymal fibrosis is compared in Table IV. Overall, a similar lobar distribution, with a propensity for upper lobe tumors, was observed in subjects with and
TABLE III. Lobe of Origin in Asbestos-Exposed Workers and Heavy Smokers: CARET Studya

\begin{tabular}{lcc} 
Smoking status $^{\mathbf{b}}$ & $\begin{array}{c}\text { Asbestos-exposed } \\
\mathbf{n}(\%)\end{array}$ & $\begin{array}{c}\text { Heavy smokers } \\
\mathbf{n}(\%)\end{array}$ \\
\hline $\begin{array}{l}\text { Ever-smokers } \\
\text { Upper lobe }\end{array}$ & $\mathrm{n}=73$ & $\mathrm{n}=167$ \\
$\quad$ Lower lobe & $49(67)$ & $133(80)$ \\
OR $^{\mathrm{d}}(95 \% \mathrm{Cl})=1.92(1.03-3.55)$ & $24(33)$ & $34(20)$ \\
Former smokers & & \\
Upper lobe & $\mathrm{n}=38$ & $\mathrm{n}=44$ \\
Lower lobe & $24(63)$ & $35(80)$ \\
OR (95\% Cl) = 2.27 (0.85-6.08) & $14(37)$ & $9(20)$ \\
Current smokers & & $\mathrm{n}=123$ \\
Upper lobe & $\mathrm{n}=35$ & $98(80)$ \\
Lower lobe & $25(71)$ & $25(20)$ \\
OR $(95 \% \mathrm{Cl})=1.57(0.66-3.69)$ & $10(29)$ & \\
\hline
\end{tabular}

aExcludes 52 cases with tumors in extralobar locations.

${ }^{\circ}$ No never smokers in asbestos-exposed cohort developed lung cancer. Includes 19 subjects developing right middle lobe tumors.

odds of tumor originating in lower lobe.

TABLE IV. Lobe of Origin Among Asbestos-Exposed Workers With and Without Radiographic Parenchymal Fibrosis at CARET Baseline

Stratified by Smoking Status

\begin{tabular}{lcc} 
Smoking status & $\begin{array}{c}\text { Fibrosis presenta } \\
\mathbf{n}(\%)\end{array}$ & $\begin{array}{c}\text { Fibrosis absent } \\
\mathbf{n}(\%)\end{array}$ \\
\hline $\begin{array}{l}\text { Ever smokers } \\
\text { Upper lobec }\end{array}$ & $\mathrm{n}=47$ & $\mathrm{n}=26$ \\
Lower lobe & $31(66)$ & $18(69)$ \\
OR ${ }^{\mathrm{d}}(95 \% \mathrm{Cl})=1.16(0.42-3.25)$ & $16(34)$ & $8(31)$ \\
Former smokers & & \\
Upper lobe & $\mathrm{n}=25$ & $\mathrm{n}=13$ \\
Lower lobe & $14(56)$ & $10(77)$ \\
OR $(95 \% \mathrm{Cl})=2.62(0.58-11.89)$ & $11(44)$ & $3(23)$ \\
Current smokers & & \\
Upper lobe & $\mathrm{n}=22$ & $\mathrm{n}=13$ \\
Lower lobe & $17(77)$ & $8(62)$ \\
OR $(95 \% \mathrm{Cl})=0.47(0.11-2.10)$ & $5(23)$ & $5(38)$ \\
\hline
\end{tabular}

alLO profusion score $\geq 1 / 0$, baseline radiograph at enrollment. blLO profusion score $<1 / 0$, baseline radiograph at enrollment. Includes 19 subjects developing right middle lobe tumors.

dOdds of tumor originating in lower lobe.

without radiographic fibrosis at baseline; no significant tendency towards lower lobe tumors was observed in participants with fibrosis $(\mathrm{OR}=1.16 ; 95 \% \mathrm{CI}=0.42-3.25)$. Although not statistically significant, a tendency towards 


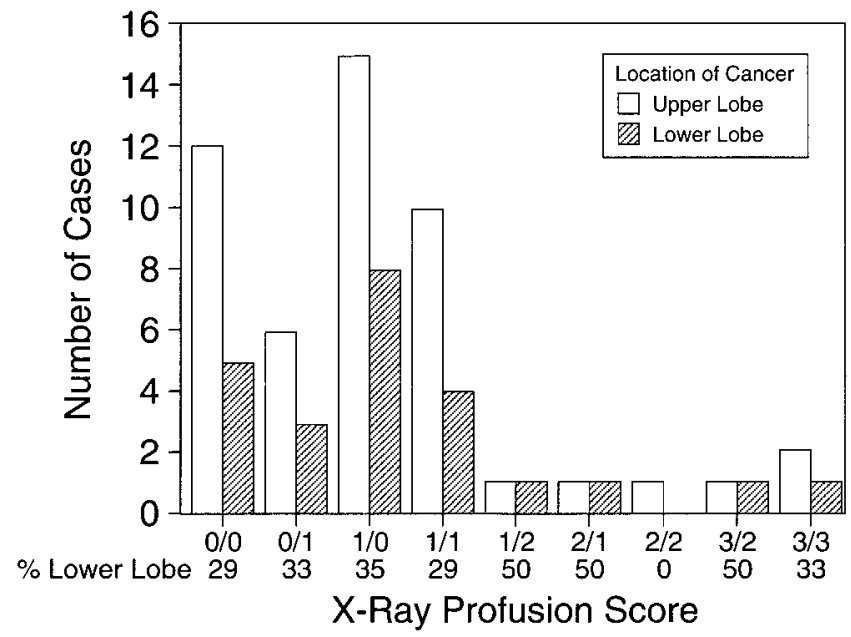

FIGURE 1. Lung tumor location by ILO category. Lobar distribution of lung tumors among asbestos-exposed participants by International Labour Office (ILO) category of radiographic parenchymal changes.

lower lobe tumors was observed in former-smoking asbestosexposed participants with radiographic fibrosis, compared to those without fibrosis, with an odds ratio of $2.62(95 \% \mathrm{CI}=$ 0.58-11.89). In contrast, this tendency was not observed among current smokers; those with radiographic fibrosis were only half as likely to develop lower tumors as participants without radiographic fibrosis $(\mathrm{OR}=0.47$; $95 \% \mathrm{CI}=0.11-2.10)$.

The lobar distribution of lung tumors among asbestosexposed participants by ILO category of radiographic parenchymal changes (profusion of small opacities) is displayed graphically in Figure 1. No increased prevalence of lower lobe tumors was observed with increasing ILO profusion category. Thirty-one percent of lung cancers were lower lobe in origin among participants without significant parenchymal changes (ILO rating <1/0), compared with 33\% among those with mild to moderate changes (ILO rating $1 / 0-1 / 2$ ) and $37 \%$ among those with severe changes (ILO rating $\geq 2 / 1$ ).

The histologic distribution of incident lung tumors in asbestos-exposed participants compared with heavy smokers is presented in Table V. No significant association between vitamin intervention arm and histologic cell type was observed [Omenn et al., 1996]; 55\% of those developing adenocarcinoma were randomized to the active arm, compared with $60 \%$ for those developing other cell types. Adenocarcinoma occurred most frequently in both asbestos and smoking cohorts, representing $32 \%$ of tumors in the asbestos-exposed cohort, and 30\% of tumors in heavy smokers. Squamous cell carcinoma was represented as frequently as adenocarcinoma in asbestos-exposed participants with and without fibrosis, but less frequently among heavy smokers, representing only $20 \%$ of tumors. Both large and small cell undifferentiated tumors were relatively more frequent in the heavy smoking cohort, representing $45 \%$ of
TABLE V. Histologic Distribution of Lung Tumors in CARET Asbestos-Exposed Workers and Heavy Smokers ${ }^{\mathrm{a}}$

\begin{tabular}{|c|c|c|c|c|}
\hline \multirow[b]{3}{*}{ Histologic type } & \multicolumn{3}{|c|}{ Asbestos-exposed workers $(n=74)$} & \multirow{3}{*}{$\begin{array}{l}\text { Heavy smokers } \\
\qquad \begin{array}{c}(n=204) \\
n(\%)\end{array}\end{array}$} \\
\hline & \multicolumn{2}{|c|}{ Fibrosis } & \multirow[b]{2}{*}{$\begin{array}{l}\text { Total } \\
\text { n (\%) }\end{array}$} & \\
\hline & $\begin{array}{c}\text { Present } \\
\text { n (\%) }\end{array}$ & $\begin{array}{c}\text { Absent } \\
\mathrm{n}(\%)\end{array}$ & & \\
\hline Adenocarcinoma & $10(22)$ & $14(50)$ & $24(32)$ & $62(30)$ \\
\hline Squamous cell & $14(30)$ & $10(36)$ & $24(32)$ & $41(20)$ \\
\hline Large cell & $9(20)$ & $3(11)$ & $12(16)$ & $48(24)$ \\
\hline Small cell & $11(24)$ & 0 & $11(15)$ & $42(21)$ \\
\hline Other ${ }^{b}$ & $2(4)$ & $1(3)$ & $3(4)$ & $11(5)$ \\
\hline
\end{tabular}

aExcludes 8 cases with mixed adenosquamous tumors and 6 cases of clinically diagnosed tumors.

'Nonspecific category, including rare neuroendocrine tumor, sarcomas, lymphoma, and other nonclassifiable tumors.

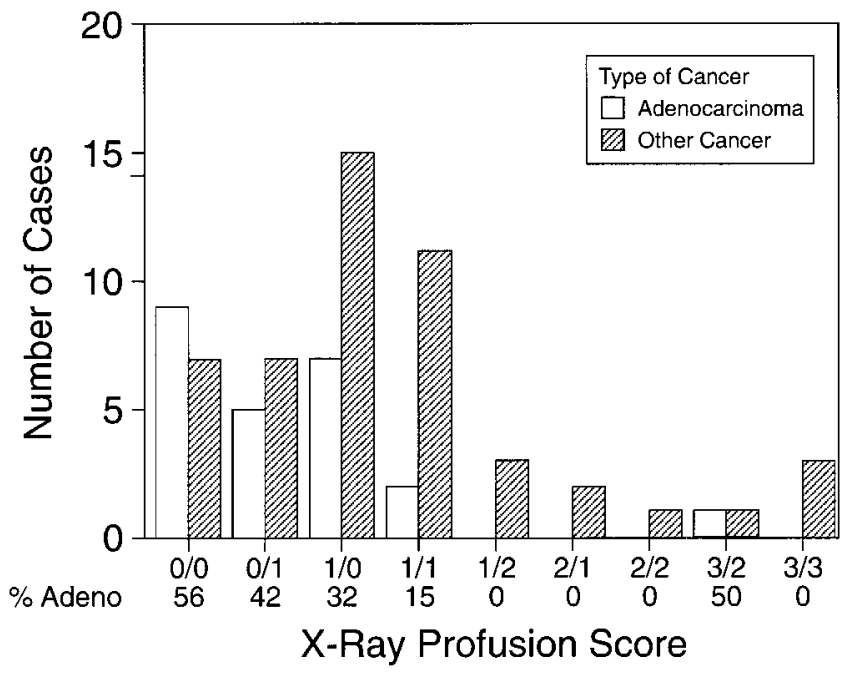

FIGURE 2. Lung tumor histologic type by ILO category. Histologic distribution of adenocarcinomas compared with other cell types among asbestos-exposed subjects by International Labour Office (ILO) category of radiographic parenchymal changes.

tumors collectively, compared with $31 \%$ of tumors in the asbestos group. Among asbestos-exposed workers, no predominance of adenocarcinoma cell type was observed in individuals with radiographic evidence of fibrosis. The histologic distribution of adenocarcinomas compared with other cell types among asbestos-exposed subjects by ILO profusion score is displayed graphically in Figure 2. Adenocarcinoma represented 50\% (14/28) of lung cancers among participants without significant parenchymal changes (ILO rating <1/0), compared with $24 \%(9 / 38)$ for those with mild to moderate changes (ILO rating 1/0-1/2), and 13\% (1/8) for those with severe changes. 
TABLE VI. Odds Ratios for Development of Lower Lobe $e^{\mathrm{a}}$ Tumor and Adenocarcinoma ${ }^{\mathrm{b}}$ Among CARET Participants Developing Lung Cancer

\begin{tabular}{|c|c|c|}
\hline & $\begin{array}{l}\text { Lower lobe of origin a } \\
\qquad \begin{array}{c}\text { ( } n=240) \\
\text { OR }(95 \% \text { Cl) }\end{array}\end{array}$ & $\begin{array}{c}\text { Adenocarcinoma }^{b} \\
(\mathrm{n}=278) \\
\text { OR }(95 \% \mathrm{Cl})\end{array}$ \\
\hline Preactors & & \\
\hline Asbestos exposure ${ }^{c}$ & $1.41(0.69-2.91)$ & $0.78(0.40-1.55)$ \\
\hline Smoking status ${ }^{d}$ & $0.88(0.46-1.70)$ & $0.61(0.34-1.09)$ \\
\hline Pack-years smoking & $1.01(1.00-1.02)$ & $0.99(0.97-1.00)$ \\
\hline Gender (female) & $0.45(0.20-1.02)$ & $0.66(0.35-1.24)$ \\
\hline Age & $1.02(0.96-1.08)$ & $0.96(0.92-1.01)$ \\
\hline Intervention arme & $0.79(0.42-1.47)$ & $0.85(0.50-1.45)$ \\
\hline
\end{tabular}

aLower lobe versus non-lower (upper or middle) lobe tumor.

${ }^{b}$ Adenocarcinoma cell type versus nonadenocarcinoma tumor histology.

'Asbestos-exposed versus heavy smoking cohort group.

${ }^{\mathrm{d} C}$ Current versus former smokers.

eActive vitamin intervention versus placebo.

Because lung cancer developed only among former and current smokers in the asbestos-exposed cohort, it was necessary to assess the association of asbestos-exposure with lower lobe tumors and adenocarcinomas, respectively, while controlling for smoking. In logistic regression analyses controlling for cumulative and current smoking status, gender, age, and vitamin intervention (Table VI), asbestosexposure was weakly associated with lobe of origin (OR $1.41 ; 95 \% \mathrm{CI}=0.69-2.91)$, and inversely associated with adenocarcinoma (OR 0.78; 95\% CI $=0.40-1.55)$. The magnitude of these associations were not affected by exclusion of female cases. Both current smoking and female gender were inversely associated with lower lobe of origin and adenocarcinoma cell type.

Logistic regression analyses of asbestos-exposed participants, assessing the relationship between radiographic changes and development of lower lobe tumor and adenocarcinoma are presented in Table VII. No significant associations between parenchymal changes or pleural thickening and lower lobe of origin were observed, after controlling for potential confounders. However, the presence of radiographic fibrosis was inversely associated with adenocarcinoma, with a significantly reduced risk for this tumor type $(\mathrm{OR}=0.19 ; 95 \% \mathrm{CI}=0.06-0.62)$. Again, current smokers were less likely than former smokers to develop lower lobe tumors $(\mathrm{OR}=0.53 ; 95 \% \mathrm{CI}=0.17-1.65)$, or adenocarcinoma cell type $(\mathrm{OR}=0.29 ; 95 \% \mathrm{CI}=0.08-1.05)$.

\section{DISCUSSION}

Despite a paucity of controlled prospective studies, lower lobe of origin and histologic cell type of adenocarcinoma are cited frequently in both clinical and medicolegal settings as useful parameters for attributing lung tumors to prior asbestos exposure. In this prospective study of asbestos-
TABLE VII. Odds Ratios for Development of Lower Lobe Tumor and Adenocarcinoma Among the CARET Asbestos-Exposed Cohort

\begin{tabular}{|c|c|c|}
\hline & $\begin{array}{l}\text { Lower lobe of origina } \\
\qquad(\mathrm{n}=73)\end{array}$ & $\begin{array}{c}\text { Adenocarcinoma }^{b} \\
(n=74)\end{array}$ \\
\hline Predictors & OR (95\% Cl) & OR (95\% Cl) \\
\hline Radiographic fibrosisc & $1.09(0.37-3.20)$ & $0.19(0.06-0.62)$ \\
\hline Pleural thickeningd & $1.30(0.42-3.95)$ & $0.56(0.17-1.91)$ \\
\hline Smoking status ${ }^{\mathrm{e}}$ & $0.53(0.17-1.65)$ & $0.29(0.08-1.05)$ \\
\hline Pack-years smoking & $1.00(0.98-1.03)$ & $0.97(0.94-1.00)$ \\
\hline Age & $0.95(0.87-1.05)$ & $0.97(0.87-1.07)$ \\
\hline Intervention arm ${ }^{f}$ & $1.16(0.39-3.40)$ & $1.18(0.35-3.93)$ \\
\hline
\end{tabular}

aLower lobe versus non-lower (upper or middle) lobe tumor.

${ }^{\mathrm{b} A d e n o c a r c i n o m a}$ cell type versus nonadenocarcinoma tumor histology.

'Radiographic fibrosis $=I L 0$ profusion score $\geq 1 / 0$ versus score $<1 / 0$.

dRadiographic pleural thickening $\geq 5 \mathrm{~mm}$ versus $<5 \mathrm{~mm}$.

eCurrent versus former smokers.

${ }^{f} A c t i v e$ vitamin intervention versus placebo.

exposed workers and nonasbestos exposed heavy smokers in the CARET, we observed only a weak association between asbestos exposure and lower lobe of origin, no significant association between asbestos-exposure and development of adenocarcinoma, and an inverse association between radiographic fibrosis and development of adenocarcinoma. Fully two-thirds of lobar lung cancers developing in asbestosexposed workers-regardless of radiographic evidence of fibrosis-originated in the upper lobes, with minimally increased risk for of lower lobe tumors after controlling for smoking and other demographic factors. Similarly, adenocarcinomas represented less than one-third of histologic cell types in asbestos-exposed and nonasbestos exposed smokers alike, while radiographic evidence of parenchymal fibrosis was inversely associated with development of adenocarcinoma.

The selective accumulation of longer asbestos fibers in the lower pulmonary lobes [Sebastien et al., 1977], and the typical lower lobe distribution of parenchymal fibrosis in asbestosis [Soutar et al., 1974], have led investigators to posit that carcinogenic effects of asbestos should predominate in the lower lobes [Weiss, 1988]. Our findings differ from several previous case-control studies in which lung cancers in asbestos-exposed individuals were observed more frequently in lower lobe distributions. Among a historical cohort of Dresden asbestos workers, Jacob and Anspach (1965) observed a 2.2 to 1 ratio of lower to upper lobe tumors, compared to a 1 to 2.5 upper lobe predominance in the general population. Other case-control studies similarly have reported a 4:1 $(n=73)$ [Hueper, 1966], 5:3 $(n=50)$ [Kannerstein and Churg, 1972], and 2.5:1 $(\mathrm{n}=108)$ [Karjalainen et al., 1993] predominance of lower lobe tumors. In a pathologic series of 65 lung tumors from workers referred to UK pneumoconiosis panels, Whitwell et 
al. [1974] observed that $78 \%$ of tumors originated in the lower lobe. Karjalainen et al. [1994] further observed an association between lower lobe of origin and tissue asbestos fiber count, with an adjusted odds ratio of $2.8(95 \% \mathrm{CI}=$ 1.2-6.2) for asbestos counts greater than $10^{6}$ fibers/gm tissue, and an odds ratio of $8.0(95 \% \mathrm{CI}=2.4-26.5)$ for asbestos counts greater than $5 \times 10^{6}$ fibers/g tissue.

As in our study, other investigations of asbestosexposed populations have not observed a lower lobe predominance of lung tumors. In a population-based study of 346 lung cancer cases, a $49 \%$ upper lobe prevalence in those reporting, compared to a $57 \%$ prevalence in those denying significant prior asbestos exposure was observed [Hillerdal et al., 1983]. In a case series of 196 lung cancer patients with occupational asbestos exposure, 101/152 (66\%) anatomically determined tumors originated in the upper lobes [Auerbach et al., 1984]. Similarly, in a series of lung cancer patients with concomitant asbestosis, only 6/17 (35\%) lower lobe tumors were observed [Huuskonen, 1978].

Conflicting findings regarding predominant histologic types of lung cancer in asbestos-exposed individuals have also been reported. Several pathologic series and casecontrol studies have observed a predominance of adenocarcinoma in asbestos-exposed populations. Among pathologic series, a prevalence of adenocarcinoma of $35 \%$ was observed in two separate studies ( $\mathrm{n}=88, \mathrm{n}=17$; respectively) [Whitwell et al., 1974; Hourihane et al., 1966]. Among case-control studies, adenocarcinoma prevalences of $19 \%$ versus $10 \%(\mathrm{n}=104)$ [Hueper, 1966], versus $31 \%$ versus $13 \%(\mathrm{n}=125)$ [Johansson and Albin, 1992], in asbestosexposed compared to nonexposed individuals have been observed. In those studies assessing a dose response, relative risks for adenocarcinoma (compared to other cell types) of 4 $(95 \% \mathrm{CI}=1.2-13.7)$ and $19(95 \% \mathrm{CI}=3-119)(\mathrm{n}=145)$, were associated with tissue asbestos body counts of 1,000 and 10,000 per gram dry weight, respectively, in one study [Mollo et al., 1995], whereas in another study, odds ratios of $4.0(95 \% \mathrm{CI}=1.8-8.6)$ and $1.6(95 \% \mathrm{CI}=0.8-3.3)$ were associated with asbestos fiber counts greater than $10^{6}$ fibers/g tissue for adenocarcinoma and squamous cell carcinoma, respectively [Karjalainen et al., 1994].

The observed association between adenocarcinoma and asbestos exposure in the above studies has supported the concept of adenocarcinoma as "scar carcinoma" formation proximal to asbestosis [Browne, 1986; Talcott et al., 1988]. Our study does not support this conclusion for two reasons: first, a predominance of adenocarcinoma was not observed among a large cohort of substantially exposed individuals; second, adenocarcinoma was significantly less prevalent in individuals with radiographic evidence of parenchymal fibrosis. The inverse association observed between radiographic fibrosis and development of adenocarcinoma among asbestos-exposed participants $(\mathrm{OR}=0.19 ; 95 \% \mathrm{CI}=0.06-$ 0.62 ), suggests that asbestosis may be associated with other tumor types, as evidenced by the higher prevalence of both small and large cell undifferentiated tumors (44\% of cases) in asbestos-exposed participants with a profusion of small opacities, compared to $11 \%$ of cases among those without radiographic evidence of fibrosis. Inferences regarding such an inverse association between asbestosis and adenocarcinoma are limited in this study by the relatively small number of participants with radiographic fibrosis, particularly in higher ILO categories, and the similar histologic distribution of tumors in asbestos-exposed participants with radiographic fibrosis compared to heavy smokers without asbestos exposure. Notably, only a modest inverse association was observed for asbestos exposure compared to heavy smoking for development of adenocarcinoma $(\mathrm{OR}=0.78$; $95 \% \mathrm{CI}=0.40-1.55)$.

Our findings are consistent with several retrospective, and one historical, cohort studies that have not observed a significantly positive association between asbestos exposure and adenocarcinoma. Among case-control studies, adenocarcinoma prevalences of $15 \%$ versus $19 \%(\mathrm{n}=196)$ [Auerbach et al., 1984], 22\% versus $18 \%(\mathrm{n}=50)$ [Kannerstein and Churg, 1972], 22\% versus $28 \%(\mathrm{n}=471$ [metanalysis]) [Churg, 1985], in cases compared with controls were observed, respectively, with a summary odds ratios (metanalysis for adenocarcinoma versus squamous tumors) of 0.93 $(95 \%$ CI $=0.69-1.25)$ [Vainio et al., 1994]. In a historical cohort study of 2,400 crocidolite workers, 22 of the 71 (31\%) incident tumors were adenocarcinoma; with a relative risk of only $1.3(95 \% \mathrm{CI}=1.0-1.7)$ per $\log \mathrm{f} / \mathrm{ml} /$ year exposure for adenocarcinoma, compared to RR of 2.1 $(95 \%$ CI $=1.0-4.3)$ for large cell tumors [de Klerk et al., 1996].

There are several possible explanations for the inconsistent findings of studies investigating lobe of origin and histologic cell type in asbestos-exposed individuals. First, the sample sizes in many studies were small, limiting any generalization about histologic and anatomic findings to other asbestos-exposed populations. Second, indices of asbestos exposure vary across studies, and have included occupational history, radiographic evidence of fibrosis, and asbestos body burden or fiber counts in pathologic series. Third, diverse methods of lung cancer case identification have been utilized; autopsy and/or surgical cases are presented in most series and case-control studies, with only one previous study utilizing a prospective cohort design. Autopsy/ surgical series and case-control studies are limited by the potential for selection and recall bias inherent in retrospective studies. Selection bias may influence findings of histologic cell type, since available cases may be limited by factors such as cancer operability, while recall bias may result in misclassification of prior asbestos exposure. A comparison of histologic cell types in series of biopsy samples, surgical specimens, and necropsy samples noted a lower proportion of adenocarcinomas in the biopsy series 
than necropsy series, with the opposite pattern for squamous cell carcinomas [Whitwell et al., 1974]. The prospective design of the current study overcomes many of these potential limitations. Importantly, CARET's endpoint process minimizes selection bias by using multiple approaches for case detection. Direct review of histologic findings by the study pathologist minimizes diagnostic misclassification. Interestingly, our results on histologic prevalence of adenocarcinoma and squamous tumors are consistent with those of the other prospective cohort study of asbestosexposed workers [de Klerk et al., 1996].

While the baseline radiographic changes used in this study do not allow a specific determination of parenchymal fibrosis at the time of subsequent tumor development, it is important to note that $29 / 78$ (37\%) of asbestos-exposed subjects developing cancer had no radiographic evidence of parenchymal fibrosis at randomization. The finding of Kipen and associates (1987), documenting histologic fibrosis in all $35(25 \%)$ lung cancer cases among asbestos insulation workers without radiographic fibrosis, suggests that many of our participants might also have subclinical fibrosis. Our findings, in conjunction with those of Kipen and others [Lidell et al., 1980; Wilkinson et al., 1995], point out the limited sensitivity of radiographic profusion changes as an approach to attributing lung cancer to occupational asbestos exposure. Further incidence studies of the CARET and other cohorts will be required to determine the specific risk of the development of cancer associated with radiographic fibrosis.

Although our study design cannot address specifically the pathogenetic mechanism for asbestos-induced carcinogenesis, which has not been fully elucidated, the observation that radiographic fibrosis is not associated with increased risk of lower lobe tumors and is inversely associated with adenocarcinoma, weighs against the hypothesis that fibrosis is an essential pathogenetic factor. Since fibrosis is primarily a lower lobe process in asbestosis, a direct correlation between increasing radiographic fibrosis and greater prevalence of lower lobe tumors would be predicted by such a theory; our observations of upper lobe predominance do not support such an association. Similarly, if asbestos fibers cause cancer by a fibrogenic process resulting in "scar" carcinomas [Auerbach et al., 1979], a positive association between fibrosis and adenocarcinoma would be predicted, while an inverse association was observed among CARET participants developing cancer.

The absence of lung cancer cases among the 132 asbestos-exposed nonsmokers is compatible with the notion that the interaction between smoking and asbestos is critical to the carcinogenic process. Our findings are consistent with hypotheses that asbestos fibers within the lung adsorb and concentrate carcinogens, such as cigarette smoke [Vaino et al., 1994], or act as a more general tumor promoter [Mossman et al., 1980:1983; Topping et al., 1980], which would increase risk of all histologic tumor types in sites throughout the lung. The finding that only one $(6 \%)$ of the prelobar bronchial tumors in CARET occurred among the asbestos cohort, compared to 17 (94\%) among smokers, correlates with asbestos fiber accumulation in distal airway sites. Our finding that current smoking was independently associated with upper lobe tumors and inversely associated with adenocarcinoma confirms a differential anatomic and histologic susceptibility to active cigarette exposure in the lung [Travis et al., 1995]. The distribution of cell types observed in the CARET heavy smoking cohort, with only a $20 \%$ prevalence of squamous tumors compared to $31 \%$ in the general population [Travis et al., 1995], does not suggest a uniquely susceptible cell population.

There are several limitations to the use of CARET participants to study asbestos-related lung cancer. First, the intervention vitamins, $\beta$-carotene and vitamin $\mathrm{A}$, might have a differential biologic effect on smokers compared with asbestos-exposed individuals, confounding our observations. Retinoids appear to play a role in maintaining respiratory epithelial differentiation, ameliorating asbestosinduced squamous metaplasia [Mossman et al., 1980, 1983]. Such confounding appears unlikely, as both univariate and multivariate analyses comparing participants taking placebo with those taking intervention vitamins, failed to demonstrate a significant intervention effect on either lobe of origin or histologic cell type.

Second, the absence of lung tumors among never smokers within the asbestos cohort does not allow a strict assessment of asbestos effects independent of smoking. If some of the cancers in the asbestos cohort were solely due to smoking and had a predominance of upper lobe locations, then the true effect of asbestos on lower lobe origin among cases attributable to asbestos alone or to the interaction of smoking and asbestos might be stronger than what was observed. However, neither cumulative nor current smoking affected the magnitude of the association between asbestos and lobe of origin in multivariate models controlling for these factors.

Third, while the asbestos cohort had significant asbestos exposure representative of many high-risk trades, specific quantitative measurements of prior asbestos exposure were unavailable. While radiographic pleural and parenchymal changes are suggestive of relatively higher exposures, the lack of specific exposure measurements, such as lung fiber burden or historical airborne monitoring data, precludes more specific assessment of dose-response.

Fourth, other demographic differences between the smoking and asbestos populations, such as age and gender, might have confounded the association between asbestos and our study endpoints. Although a higher proportion of adenocarcinomas has been reported in females [Wynder et al., 1977; Travis et al., 1995], female gender was inversely associated with adenocarcinoma in the current study. Since none of the asbestos-exposed subjects was female, the 
negative association of female gender with adenocarcinoma would only have enhanced any difference between the asbestos-exposed and smoking cohorts. Confounding effects of age and gender appear unlikely, given the minimal impact of these demographic variables on the relationship between asbestos exposure and lobe of origin or histologic cell type in multivariate analyses, and in analyses excluding female cases.

In conclusion, lung cancers originated more frequently in the upper pulmonary lobes in both asbestos-exposed and nonexposed participants in the Carotene and Retinol Efficacy Trial, without a predominant histologic cell type. Asbestos-related carcinogenesis arises from a complex cascade of cellular events, set in motion when asbestos fibers are deposited and subsequently transported throughout the lung. Medicolegal questions surrounding lobe of origin and histologic type cannot be answered epidemiologically in the absence of a better understanding of these pathogenetic mechanisms. Our findings give further support to those concluding that neither lobe of origin nor tumor histology can be used convincingly to determine asbestos-related causation of lung cancer.

\section{ACKNOWLEDGMENTS}

The authors thank Barbara Metch, Ph.D., for her assistance with statistical analysis, and Gary Goodman, M.D., and Andrew Glass, M.D., for their clinical assistance in characterizing tumor lobe of origin and histologic type. CARET is supported by grants U01 CA63673, U01 CA63674, U01 CA47989, U01 CA48200, U01 CA48203, U01 CA48196, and U01 CA52596 from the National Cancer Institute.

\section{REFERENCES}

Auerbach O, Garfinkel L, Parks VR (1979): Scar carcinoma of the lung. Cancer 43:636-642.

Auerbach O, Garfinkel L, Parks VR, Conston AS, Galdi VA, Joubert L (1984): Histologic type of lung cancer and asbestos exposure. Cancer 54:3017-3021.

Barnhart S, Keogh J, Cullen MR, Brodkin C, Liu D, Goodman G, Valanis B, Glass A, Thornquist M, Rosenstock L, Omenn G, Balmes J (1997):The CARET asbestos-exposed cohort: Baseline characteristics and comparison to other asbestos-exposed cohorts. Am J Ind Med (in press).

Brodkin CA, Barnhart S, Anderson G, Checkoway H, Omenn GS, Rosenstock L (1993): Correlation between respiratory symptoms and pulmonary function in asbestos-exposed workers. Am Rev Respir Dis 148:32-37.

Browne K (1986): Is asbestos or asbestosis the cause of the increased risk of lung cancer in asbestos workers? Br J Ind Med 43:145-149.

Churg A (1985). Lung cancer cell type and asbestos exposure. JAMA 253:2984-2985.

Craighead JE, Mossman BT (1982): The pathogenesis of asbestos associated diseases. N Engl J Med 306:1446-1455.
Dail DH, Hammar SP (eds) (1988): "Pulmonary Pathology.” New York: Springer-Verlag.

de Klerk NH, Musk AW, Eccles JL, Hansen J, Hobbs MST (1996): Exposure to crocidolite and the incidence of different histological types of lung cancer. Occup Environ Med 53:157-159.

Harris RE, Zang EA, Anderson JI, Wynder EL (1993): Race and sex differences in lung cancer risk associated with cigarette smoking. Int J Epidemiol 22:592-599.

Hillerdal G, Karlen E, Aberg T (1983): Tobacco consumption and asbestos exposure in patients with lung cancer: A three year prospective study. Br J Ind Med 40:380-383.

Hourihane DOB, McCaughey WTE (1966): Pathological aspects of asbestosis. Postgrad Med J 42:613-622.

Hueper WC (1966): “Occupational and Environmental Cancer of the Respiratory System in Recent Results in Cancer Research." Vol. 3. New York: Springer-Verlag, pp 38-56.

Hughes JM, Weill H (1991): Asbestosis as a precursor of asbestos related lung cancer: Results of a prospective mortality study. Br J Ind Med 48:229-233

Huuskonen MS (1978): Clinical features, mortality and survival of patients with asbestosis. Scand J Work Environ Health 4:265-274.

International Labour Office (1980): "Guidelines for the Use of the ILO International Classification of Radiographs of Pneumoconioses." Geneva: International Labour Office.

Jacob G, Anspach M (1965): Pulmonary neoplasms among Dresden asbestos workers. Ann NY Acad Sci 132:536-538.

Johansson L, Albin M (1992): Histological type of lung carcinoma in asbestos cement workers and matched controls. Br J Ind Med 49:626-630.

Kannerstein M, Churg J (1972): Pathology of carcinoma of lung cancer associated with asbestos exposure. Cancer 30:14-21.

Karjalainen A, Anttila S, Heikkilä L, Kyyrönen P, Vaino H (1993): Lobe of origin of lung cancer among asbestos-exposed patients with or without diffuse interstitial fibrosis. Scand J Work Environ 19:102-107.

Karjalainen A, Anttila S, Vanhala E, Vaino H (1994): Asbestos exposure and the risk of lung cancer in a general urban population. Scand J Work Environ Health 20:243-250.

Kipen HM, Lilis R, Suzuki Y, Valciukas JA, Selikoff IJ (1987): Pulmonary fibrosis in asbestos-exposed insulation workers with lung cancer: A radiological and histopathological evaluation. Br J Ind Med 44:96-100.

Lidell FDK, McDonald JC (1980): Radiological findings as predictors of mortality in Quebec asbestos workers. Br J Ind Med 37:257-267.

Mollo F, Pira E, Piolatto G, Bellis D, Builo P, Andreozzi A, Bentempi S, Negri E (1995): Lung adenocarcinoma and indicators of asbestos exposure. Int J Cancer 60:289-293.

Mossman BT, Ezerman EB, Adler KB, Craighead JE (1980): Isolation and spontaneous transformation of cloned lines of hamster tracheal epithelial. Cancer Res 40:4403-4409.

Mossman BT, Craighead JE, MacPherson BV (1980): Asbestos-induced epithelial changes in organ cultures of hamster trachea: Inhibition by retinyl methyl ether. Science 207:311-313.

Mossman B, Light W, Wei E (1983): Asbestos: mechanisms of toxicity and carcinogenesis in the respiratory tract. Annu Rev Pharmacol Toxicol 23:595-675.

Omenn GS, Goodman GE, Thornquist MD, Rosenstock L, Barnhart S, Gylys C, Metch B, Lund B (1993): The Carotene and Retinol Efficacy Trial 
(CARET) to prevent lung cancer in high risk populations: Pilot study with asbestos-exposed workers. Cancer Epidemiol Biomarkers Prev 2:381-387.

Omenn GS, Goodman GE, Thornquist M, Grizzle J, Rosenstock L, Barnhart S, Balmes J, Cherniack M, Cullen M, Glass A, Keogh J, Meyskens F Jr, Valanis B, Williams J Jr (1994): The $\beta$-Carotene and Retinol Efficacy Trial (CARET) for chemoprevention of lung cancer in high risk populations: smokers and asbestos-exposed workers. Cancer Res 54(suppl):2038s2043s.

Omenn GS, Goodman GE, Thornquist MD, Balmes J, Cullen M, Glass A, Keogh JP, Meyskens FL, Valanis B, Williams JH, Barnhart S, Hammar S (1996): Effects of a combination of beta carotene and vitamin A on lung cancer and cardiovascular disease. N Engl J Med 334:1150-1155.

Omenn GS, Goodman GE, Thornquist MD, Balmes J, Cullen MR, Glass A, Keogh JP, Meyskens FL, Valanis B, Williams JH, Barnhart S, Cherniack MG, Brodkin CA, Hammar S (1996): Risk factors for lung cancer and for intervention effects in CARET, the beta-carotene and retinol efficacy trial. $\mathrm{J}$ Natl Cancer Inst 88:1550-1559.

Risch HA, Howe GR, Jain M, Burch JD, Holoway EJ, Miller AB (1993): Are female smokers at higher risk for lung cancer than male smokers? Am J Epidemial 138:281-291.

SPSS for Windows, Release 6.1 (1995): Norusis MJ (ed): "Base System Users Guide.” SPSS, Inc. 444 N. Michigan Avenue, Chicago, IL 60611.

Sébastien P, Fondimare A, Bignon J, Monchaux G, Desbrdes J, Bonnaud G (1977): Topographic distribution of asbestos fibers in human lung in relation to occupational and non-occupational exposure. In Walton WH, McGoverd B (eds): "Inhaled Particles." Vol. IV. New York: Pergamon Press, pp 435-444.
Sébastien P, Armstrong B, Monchaux G, Bignon J (1988): Asbestos bodies in bronchoalveolar lavage fluid and in lung parenchyma. Am Rev Respir Dis 137:75-78.

Soutar CA, Simon G, Turner-Warwick M (1974): The radiology of asbestos-induced disease of the lungs. Br J Dis Chest 68:235-252.

Talcott JA, Antman KH (1988): Asbestos-related malignancy. Curr Probl Cancer 12(3):135-178.

Topping, DC, Nettesheim, P (1980): Two-stage carcinogenesis studies with asbestos in Fischer 344 rats. J Natl Cancer Inst 65:627-630

Travis WD, Travis LB, Devesca S (1995): Lung cancer. Cancer 75(suppl): 191-201.

Vaino H, Boffetta P (1994): Mechanisms of the combined effect of asbestos and smoking in the etiology of lung cancer. Scand J Work Environ $20: 235-242$

Weiss W (1988): Lobe of origin in the attribution of lung cancer to asbestos. Br J Ind Med 45:544-547.

Whitwell F, Newhouse ML, Bennett DR (1974): A study of the histological cell types in workers suffering from asbestosis in the United Kingdom. Br J Ind Med 31:298-303.

Wilkinson P, Hansell DM, Janssens J, Rubens M, Rudd RM, Taylor AN (1995): Is lung cancer associated with asbestos exposure when there are no small opacities on the chest radiograph? Lancet 345:1074-1078.

Wynder EL, Stellman SD (1977): Comparative epidemiology of tobaccorelated cancers. Cancer Res 37:4608-4622. 